\title{
As condições de vida e de trabalho da população em situação de rua do centro histórico de Salvador, Bahia
}

\author{
Homelessnes conditions in Salvador, Brazil
}

\author{
Renata Meira Veras ${ }^{1}$ \\ Gezilda Borges de Souza ${ }^{2}$ \\ Brian Teles Fonseca de Macedo ${ }^{3}$ \\ Daisy Kitaoka Guerra ${ }^{4}$
}

\begin{abstract}
Resumo
Há cerca de 4 mil pessoas desabrigadas em Salvador, a maioria delas vivendo nas ruas, em condições insalubres de sobrevivência. Por meio da abordagem quantitativa e de um estudo etnográfico, esta pesquisa teve como objetivo investigar as condições de vida e de trabalho da população em situação de rua. Os resultados mostraram que a maioria das pessoas em situação de rua, em Salvador, é do sexo masculino, negra, em idade produtiva e com baixo nível educacional. Dentre as principais causas que as levam a essa condição está a ruptura dos laços familiares. Contudo, a pesquisa etnográfica revelou fatores que determinaram a quebra do vínculo familiar, como o desemprego, o uso de drogas, a violência familiar, a orientação sexual, a morte ou a separação de um dos cônjuges. Os resultados apresentados reforçam a necessidade de ir além das políticas básicas de assistência social para essa população. É necessário repensar as causas estruturais que levam à situação de rua e planejar adequadamente uma abordagem preventiva para evitá-las.
\end{abstract}

Palavras-chave: População em situação de rua. Desigualdade econômica. Vínculos familiares.

\begin{abstract}
There are about four thousand homeless people in Salvador, most of them living in the streets in extreme poverty. Through a quantitative and ethnographic approach, the research to be presented aimed to investigate the living and working conditions of this population. The results show that most homeless people in Salvador are male, black, poorly educated and in the productive age. The main causes of homeless conditions observed among this population are lack of family bonds. However, ethnographic research revealed that most homeless participants lost their family contacts because any purpose such as unemployment, drug use, family violence, sexual orientation, separation or death of a spouse. Therefore, our results reinforce

\footnotetext{
1 Universidade Federal da Bahia (UFBA). Professora Adjunta do Instituto de Humanidades, Artes e Ciências, UFBA. E-mail: renata.veras@ufba.br.

2 Universidade Federal da Bahia (UFBA). Mestranda pelo Programa de Pós-graduação em Estudos Interdisciplinares sobre a Universidade - IHAC/UFBA. E-mail: gelborges@hotmail.com.

${ }^{3}$ Universidade Federal da Bahia (UFBA). Mestrando pelo Programa de Pós-graduação em Estudos Interdisciplinares sobre a Universidade - IHAC/UFBA. E-mail: macedo_brian@hotmail.com.

4 Universidade Federal da Bahia (UFBA). Bacharel em Artes - IHAC/UFBA. E-mail:
} daisykitaoka@gmail.com.
\end{abstract}


the need of going beyond social assistance politicies, such as providing public social dwellings or boarding spaces. It is necessary to rethink about the structural causes of homelessness and plan accordingly a preventive approach to avoid the homeless conditions.

Keywords: Homelessness. Economic inequality. Family bonds.

\section{Introdução}

No Brasil, as décadas de 1970 e 1980 foram marcadas por profundas transformações provocadas pelo capitalismo. O trabalho ocupou o centro dessas transformações. Destacam-se, entre outros fatores, as mudanças no mundo do trabalho, cujos efeitos mais evidentes foram o agravamento do desemprego, da precarização das relações e das condições de trabalho e a queda da renda média dos trabalhadores. Paralelamente a isso, o êxodo rural também contribuiu para uma expressiva superpopulação relativa, que aumentou os níveis de pobreza e vulnerabilidade da classe trabalhadora. É nesse cenário que se observa o crescimento de pessoas vulneráveis à situação de rua nos grandes centros urbanos (ROSA, 2005; DE SÁ, 2008).

A partir da articulação de movimentos sociais em favor desses indivíduos, na década de 1990, esse grupo vulnerável impulsionou a instituição de uma nova modalidade de política pública, comprometendo o Estado com sua implementação. Isso foi notável, uma vez que as ações dirigidas a essa população ficaram historicamente delegadas ou às organizações privadas da sociedade civil ou ao Estado, que intervinha nessa situação, com posturas de caráter assistencialista ou de "limpeza" (ROSA, 2005).

No entanto, observa-se que as condições de vida da população, em situação de rua, ainda são pouco conhecidas no Brasil. De forma geral, as pesquisas oficiais do governo ignoram esses indivíduos em suas estatísticas. Isso pode ser justificado, principalmente, pela dificuldade em definir e mensurar esse segmento populacional, já que não possuem endereço fixo. Por esse motivo, a população em situação de rua nunca foi incluída em censos oficiais do Instituto Brasileiro de Geografia e Estatística (IBGE).

Assim, a partir dos movimentos sociais e com o envolvimento do Estado com essa população, em 2008, o Ministério do Desenvolvimento Social e Combate à Fome (MDS) organizou a Pesquisa Nacional sobre a População em Situação de Rua em 71 cidades brasileiras. Os resultados dessa pesquisa indicaram um total de 
31.922 indivíduos adultos nessa situação. A cidade de Salvador, local desta pesquisa, possuía, em 2008, cerca de 3,3 mil pessoas vivendo em situação de rua. Em 2011, estimava-se mais de 4 mil pessoas vivendo nessa situação (BAHIA, 2011).

Além disso, os dados coletados demonstraram que essas pessoas vivem expostas a condições difíceis de sobrevivência no que diz respeito à habitação, à alimentação, ao trabalho, à higiene e aos vínculos sócio familiares e saúde, refletindo, dessa forma, a enorme desigualdade econômica existente no país (AGUIAR, 2010; BRASIL, 2008a).

A pesquisa do MDS (BRASIL, 2008a) buscou traçar um perfil dessa população, reconhecendo-a como um grupo populacional heterogêneo constituído por pessoas que possuem em comum a garantia da sobrevivência, por meio de atividades produtivas desenvolvidas nas ruas, dos vínculos familiares interrompidos ou fragilizados e da não referência de moradia regular.

A população em situação de rua passou, assim, a ser conceituada, como um segmento de baixíssima renda que, por contingência temporária ou de forma permanente, pernoita nos logradouros da cidade - praças, calçadas, marquises, jardins, embaixo de viadutos, locais abandonados, terrenos baldios, mocós, cemitérios e carcaças de veículos. Acrescenta-se também a esse grupo aqueles que pernoitam em albergues públicos ou de organizações sociais (BRASIL, 2008a; BRASIL, 2008b).

No entanto, reconhece-se que o conceito de população em situação de rua se apresenta, de fato, como polissêmico e genérico, apresentando deficiências e insuficiências para compreender a complexidade do que significa viver nas ruas (ROSA, 2005). Nessa perspectiva, tendo em vista a necessidade de se ampliar o escopo de investigações sobre a população em situação de rua, este estudo teve como objetivo traçar um perfil da população em situação de rua que habita o Centro Histórico da Cidade de Salvador, no intuito de contribuir para a construção e/ou reestruturação de políticas públicas voltadas para essa população.

\section{Percurso metodológico}

Para atender ao objetivo desta pesquisa, foram empreendidos dois tipos de estudos. Para caracterização do perfil da população em situação de rua de Salvador foi aplicada a metodologia quantitativa. Para tanto, foi construído e validado um Cad. de Pesq. Interdisc. em Ci-s. Hum-s., Florianópolis, Santa Catarina, ISSN 1984-8951 
questionário. Esse instrumento foi aplicado em 195 indivíduos em situação de rua, contendo perguntas referentes a características socioeconômicas, formação escolar, trabalho, renda e condições de saúde. Após a assinatura do Termo de Consentimento Livre e Esclarecido, os questionários foram aplicados no mês de janeiro de 2011, no período noturno (entre $19 \mathrm{~h}$ e $22 \mathrm{~h}$ ), tendo em vista ser esse o horário no qual a população de rua retorna ao local escolhido para pernoitar. Com o apoio do Movimento Nacional da População de Rua (Salvador-Bahia), ${ }^{5}$ os indivíduos foram identificados e entrevistados em três regiões indicadas pelo movimento:

- $\quad$ região do Centro I - Praça Municipal, Praça Castro Alves, Avenida Sete de Setembro: Relógio de São Pedro, Piedade, Campo Grande e Corredor da Vitória;

- região do Centro II - Barroquinha, Baixa dos Sapateiros, Aquidabã, Dois Leões e Nazaré; e

- $\quad$ região da Cidade Baixa III - Comércio e Água de Meninos: Feira de São Joaquim, Calçada, Praça dos Mares, Largo de Roma e Igreja da Trindade (situada na Avenida Jequitaia, na qual são acolhidas cerca de 50 pessoas em situação de rua).

Paralelamente a esta pesquisa quantitativa, também foi desenvolvido um estudo etnográfico no intuito de compreender com profundidade as condições de vida e de trabalho da população em situação de rua. Foram realizadas observações participantes no período de 4 meses, registradas em diários de campo. Além disso, foram aplicadas entrevistas semiestruturadas com 10 indivíduos sobre o modo de vida dessa população, sendo 7 do sexo masculino e 3 do sexo feminino em situação de rua. As entrevistas foram realizadas no Projeto Levante-te e Anda, ${ }^{6}$ na Comunidade da Trindade,$^{7}$ na Praça da Piedade e no Bairro Garcia.

Os dados quantitativos foram analisados por meio do programa estatístico SPSS/PC, a fim de apresentar as médias e proporções das respostas da população de rua. Já os dados qualitativos foram analisados via análise de discurso proposta por Willig (2008).

\footnotetext{
${ }^{5}$ O Movimento da População Nacional de Rua luta em defesa dos direitos e por politicas públicas para a população em situação de rua.

${ }^{6}$ O Projeto "Levanta-te e Anda" é um Centro de Convivência diurno que acolhe a população em situação de rua, objetivando o desenvolvimento de habilidades, o resgate da dignidade da pessoa humana e a cidadania.

${ }^{7}$ A Comunidade da Trindade é um local que acolhe pessoas em situação de rua. O espaço é uma Igreja Católica do Século XVIII que estava abandonada.
} 


\section{Resultados e discussão}

A partir da análise dos dados da pesquisa foram construídos eixos temáticos, com objetivo de agrupar os materiais coletados, segundo suas especificidades. Os eixos foram nomeados como: (a) dados sócio-demográficos (gênero, etnia, estado civil, naturalidade e distribuição etária da população); (b) educação, trabalho e renda (escolaridade, cursos de qualificação e experiências de trabalho, os tipos de atividades remuneradas exercidas nas ruas e a renda); (c) permanência nas ruas (tempo de permanência nas ruas e fatores que motivaram as pessoas a residirem nas ruas); e (d) saúde (existência de problemas de saúde e os serviços procurados quando necessitam de atendimento médico).

\subsection{Dados sócio-demográficos}

No eixo sócio-demográfico foram analisados os aspectos que conferem certas especificidades sobre a população em situação de rua, na cidade de Salvador.

Quanto à questão gênero, verificou-se que há uma predominância do sexo masculino, uma vez que apenas $15 \%$ dessa população é composta por mulheres. Varanda e Adorno (2004) oferecem como uma das possíveis justificativas para a presença majoritária masculina nas ruas o fato de que em famílias de classes menos abastadas geralmente o homem é o principal provedor financeiro. Com o desemprego, o homem passa a buscar o sustento das famílias, trabalhando nas ruas, ou então ele abandona a família por se sentir incapaz de realizar o papel de provedor. Por outro lado, também se atenta para o fato de que existe maior aceitação de mulheres em trabalhos domésticos, sendo socialmente classificadas como mais confiáveis de se abrigar do que os homens.

A definição étnica das pessoas em situação de rua apresentou grande complexidade na apuração dos dados. Isso porque, o Brasil e, sobretudo, a cidade de Salvador, tem uma forte característica de miscigenação, o que dificulta a forma de precisar a cor de qualquer indivíduo. Essa miscigenação não interfere apenas na classificação da cor da pele, mas também envolve toda uma construção de identidade, em que o sujeito se classifica quanto ao sentimento de pertencimento. As respostas revelaram que $56 \%$ dos indivíduos entrevistados se consideram negros 
e apenas $9 \%$ se dizem brancos. Já em relação à cor parda, esta corresponde a $34 \%$ dos entrevistados.

A respeito do estado civil, 64\% dos entrevistados afirmaram estar solteiros, $22 \%$ possuírem um(a) companheiro(a), 11\% separados e $2 \%$ viúvos. Verificou-se que a maior parte dos entrevistados que possuem companheiro(a) estabeleceu esse vínculo no próprio ambiente das ruas. Para as mulheres, principalmente, a relação afetiva pode ser iniciada como uma estratégia de proteção para as dificuldades encontradas na condição de rua. Corroboram com esse achado os estudos de Varanda e Adorno (2004), que apresentam a vulnerabilidade feminina como um fator decisivo para o abuso e a exploração sexual nas ruas.

Constatou-se também que a maior parte dessa população é natural da própria cidade de Salvador (116 indivíduos dentre as 195 entrevistadas). Sendo assim, afasta-se a hipótese de que as pessoas em situação de rua são oriundas de outros estados.

Os dados analisados também confirmaram que a maior parte da população de rua entrevistada (82\%) está inserida em uma faixa etária em que poderia ser classificada como uma população economicamente ativa, ou seja, pessoas com idade entre 19 e 49 anos aptas a contribuir para o setor produtivo. Destaca-se também que apenas $10 \%$ dessa população tem mais de 50 anos, o que suscita que a exposição a ambientes insalubres e à violência nas ruas podem ser uma explicação para a baixa expectativa de vida das pessoas em condição de rua.

\subsection{Educação, trabalho e renda}

No que diz respeito ao grau de escolaridade das pessoas em situação de rua, os dados coletados mostraram que aproximadamente $70 \%$ dos entrevistados possuem apenas o ensino fundamental ( $1^{a}$ até a $8^{a}$ série), sendo que $39 \%$ destes cursaram até a $4^{a}$ série. Sendo assim, constata-se que essa população se caracteriza por uma baixa escolaridade.

Por outro lado, contrastando com esses dados, com a pesquisa qualitativa foi possível entrevistar um ex-morador em situação de rua que atualmente é estudante da Universidade Federal da Bahia. Este indivíduo afirmou que possui o hábito de frequentar a Biblioteca Pública e eventos culturais: 
Vou ao cinema nos Barris. Tem filmes de graça no Espaço XIS. Também tenho acesso à biblioteca pública e pego livros... Onde tem shows de música de graça eu também vou, tem o Pelô (Pelourinho), o de Gerônimo. $(R, 32$ anos, ex-morador em situação de rua e atualmente estudante da UFBA).

Apesar da baixa escolaridade, constatou-se também que uma considerável parcela dessa população $(66 \%)$ possui algum tipo de qualificação profissional e/ou alguma experiência no mercado de trabalho, podendo ter sido obtida antes ou durante a sua estada nas ruas. Esses dados desmistificam, portanto, o estigma que a sociedade impõe de que esse segmento é composto exclusivamente por pessoas despreparadas para estabelecer vínculos empregatícios. As áreas de qualificação apontadas pelos entrevistados estão relacionadas com a construção civil que correspondem a $35 \%$ do total, seguida por atendimento/vendas e artesanato, ambos com $11 \%$; mecânica de automóveis em torno de $7 \%$; salão de beleza com $6 \%$; e reciclagem $2 \%$.

Nas entrevistas semiestruturadas, o relato seguinte comprova a qualificação em cursos profissionalizantes:

Comecei a trabalhar em reforma de prédio, eu fazia tudo de prédio, tudo! Fiz curso de marcenaria, de vidraceiro... Hoje não faço nada disso. Não encontro trabalho. Vendo plantas medicinais para sobreviver (CB, 50 anos, em situação de rua).

Os dados coletados na pesquisa mostraram que, independentemente de possuírem cursos de qualificação profissional, as pessoas em condição de rua desenvolvem outras atividades como forma de obter alguma renda. Dentre essas atividades, destacam-se a coleta de lixo para a reciclagem (34\%), guardadores de carro $(18 \%)$ e outros tipos de trabalho informal $(28 \%)$. Vale ressaltar que $3 \%$ dos entrevistados admitiram praticar pequenos furtos como forma de sustento na rua.

Deve-se observar também que, enquanto a coleta de lixo para a reciclagem corresponde a $34 \%$ das atividades atualmente desenvolvidas por essas pessoas, apenas $2 \%$ das pessoas em situação de rua afirmaram ter feito um curso de qualificação em reciclagem dos materiais coletados, possivelmente por entenderem que para esse tipo de atividade não há necessidade de qualificação. Entende-se que o objetivo da coleta dos materiais recicláveis é a venda para a sua subsistência.

Ao se questionar acerca dos principais empecilhos para se desenvolver uma atividade formal, $34 \%$ da população entrevistada apontou a falta de documentação 
pessoal, seguida pela falta de comprovante de residência (12\%), pela falta de qualificação (11\%), pelas questões psicológicas e de saúde (10\%), pelo uso frequente de drogas e bebidas $(10 \%)$ e, por último, pela idade $(9 \%)$.

Esses resultados foram reforçados pelos discursos coletados nas entrevistas semiestruturadas:

\begin{abstract}
Sou cabeleireiro, sou manicure e artesão. Às vezes pego alguma coisa no lixo e reciclo para usar. Um tamanco. Sabe, morando na rua a gente perde a vontade de fazer as coisas, até em tirar os documentos. Eu não tenho meus documentos, eles foram roubados (PS, 27 anos, em situação de rua).

Eu trabalhei no Jornal O Globo, depois que eu saí de lá em 72,73 , eu fui pra São Paulo, trabalhei no metrô, trabalhei bastante lá, também. Sempre tive onde morar... chegava numa cidade, alugava um quarto, trabalhava, vendia coisa na rua, sou vendedor ambulante, mas agora, estou na rua, literalmente. Não consigo mais emprego por causa da minha idade. Trabalho hoje pra comer amanhã... Cheguei aqui com uns $\mathrm{R} \$ 30,00 \ldots$ Mas estou fazendo reciclagem agora. (FC, 60 anos, em situação de rua).
\end{abstract}

Em decorrência da dificuldade em adquirir trabalho, o relato da moradora em situação de rua aponta o tráfico de drogas e a prostituição como meio de vida:

Eu queria trabalhar, mas quando eu mostrava minhas referências de Pernambuco, as pessoas me diziam que não serviam pra aqui, então eu fui traficar drogas. Conheci uns traficantes, mas traficar foi apenas o começo, daí comecei a usar drogas e me prostituir, mas cansei [...] eu fui aplicar o golpe de Boa Noite Cinderela e terminei presa, fiquei um ano e nove meses, agora eu tô limpa... (ME, 34 anos, ex-moradora em situação de rua).

No que se refere à renda adquirida por essas pessoas, verificou-se que $48 \%$ da população entrevistada vive com 200 (duzentos) reais por mês, o que equivale a menos de 7 (sete) reais por dia. Esses dados corroboram com os achados de Escorel (2006), que afirma que essa população excluída, fragilizada e desprotegida se constitui por uma inserção ocupacional irregular de baixos rendimentos e informal.

Em consonância com os depoimentos dos entrevistados, o MPR-BA destacou que a maioria das pessoas por ele representadas não possui todos os seus documentos, pois são furtados, perdidos, destruídos nas ruas e, em alguns casos, inexistentes. Diante dessa constatação, a Defensoria Pública da Bahia iniciou o atendimento individual das pessoas em situação de rua desprovidas de documentação, viabilizando a expedição de segundas vias daqueles que os 
possuíam e a orientação e encaminhamento para a regularização dos desprovidos de tais instrumentos básicos para o exercício da cidadania (BAHIA, 2011).

A atuação da Defensoria Pública também foi decisiva para que o MPR-BA conseguisse que pessoas em situação de rua fossem contratadas como trabalhadores da construção civil, no canteiro de obras da Arena da Fonte Nova, e viabilizasse a inclusão de pessoas em situação de rua no Programa Minha Casa Minha Vida (BAHIA, 2011).

\subsection{Permanência nas ruas}

Em relação ao tempo de permanência nas ruas, os resultados apontam para o fato de que $15,9 \%$ das pessoas entrevistadas estão entre cinco e dez anos nas ruas, enquanto $43,6 \%$ dos indivíduos entrevistados vivem nas ruas há mais de dez anos. Portanto, mais de $60 \%$ dessas pessoas já estão nas ruas há mais de cinco anos. Esse dado é de suma importância, pois revela a dificuldade da maioria das pessoas em situação de rua para sair desse contexto.

Um dos aspectos centrais da pesquisa foi a compreensão dos fatores que motivaram as pessoas a se inserirem em uma condição social marcada por uma vida cheia de riscos e sem respeito à dignidade humana. As respostas revelaram que as relações familiares se apresentam como principal propulsor para a situação de rua (50,2\% dos entrevistados). Portanto, mais da metade dos entrevistados afirmou que o principal motivo de morar nas ruas foi ocasionado por problemas familiares, e, em segundo lugar, as questões referentes ao desemprego (13\%) e ao uso de drogas $(13 \%)$.

A maior parte dos discursos coletados pela pesquisa qualitativa também apontou os problemas familiares como o principal motivo para irem às ruas. S é uma ex-moradora em situação de rua, 44 anos, mãe aos 13 anos e avó de três crianças. Atualmente, mora em um quarto alugado, mantém-se com doações e venda de água mineral no Pelourinho:

Sou S, sou baiana de Salvador do bairro de Cosme de Farias. Eu brigava muito com meu marido, depois da separação fui parar nas ruas [...] caí nas ruas por causa da separação do marido [...] aí fui morar nas ruas com minha filha, me entreguei nas drogas... na cachaça... eu não quero mais voltar ter aquela vida. 
De acordo com Rosa (2005), as rupturas familiares relacionadas à morte ou à separação do cônjuge são vistas pelos entrevistados como responsáveis pela mudança de rumo em suas vidas, uma vez que os vínculos com outros membros da família eram inexistentes ou fragilizados e comprometidos pelos atritos na disputa de espaço familiar.

O depoimento de $A C$ em situação de rua também apontou problemas familiares como principal motivo para sair de casa. AC, 25 anos, é o filho mais velho de uma família de quatro irmãos, sendo que dois moram com a mãe e dois com a avó. Ele contou que sempre sofreu violência doméstica e por esse motivo saiu de casa aos seis anos de idade: "eu não aguentei ser saco de pancada do meu pai". A avó era sua referência afetiva: "eu preferia ir para a casa da minha vó e depois saía para as ruas", ele afirma.

A fragilidade dos laços familiares, tendo a pobreza como pano de fundo, é uma das características comuns aos indivíduos em situação de rua. De acordo com Sarti (2009), a família não é apenas o elo afetivo mais forte da população menos favorecida, o núcleo da sua sobrevivência material e espiritual, o instrumento pelo qual viabilizam seu modo de vida, mas o próprio substrato de sua identidade social. Igualmente, essa pesquisa corrobora com a de Escorel (1998) realizada em Porto Alegre, que apontou problemas de relacionamento familiar como $30 \%$ dos motivos para as pessoas irem morar nas ruas.

Por outro lado, ressalta-se que os motivos para as pessoas se tornarem vulneráveis à situação de rua são bastante complexos, indo desde fatores estruturais, que abrangem a ausência de moradia e a inexistência de trabalho e renda, a fatores biográficos, como rompimento de vínculos familiares, uso de álcool e outras drogas, doenças mentais e até fatores políticos, como a falta de assistência para a população vulnerável. Atenta-se para o fato de que o rompimento de vínculos familiares, muitas vezes, está encoberto por outros fatores, como a violência familiar, o abandono, o uso de álcool e drogas e, principalmente, o desemprego. Consequentemente, o desemprego destitui o poder relacionado à figura de chefe de família, levando à situação de rua, principalmente, os homens (ESCOREL, 2006; SILVA, 2006).

Para Rosa (2005), as vidas das pessoas em situação de rua denuncia, de um lado, o fracasso das políticas públicas sociais brasileiras e, de outro, a ausência e o 
descaso das instituições, que abandonam essas famílias, geralmente vistas pela sociedade como pais desumanos que abandonaram seus filhos.

Os resultados obtidos pela pesquisa etnográfica demonstraram que os problemas familiares apontados pelas pessoas em situação de rua tiveram origens diversas, entre outras, o desemprego, o uso de drogas, a violência familiar, a orientação sexual, a morte ou a separação de um dos cônjuges. As duas histórias relatadas a seguir, aparentemente diferentes, aproximam-se por aspectos dramaticamente problemáticos "à homossexualidade e à violência doméstica":

Fico com saudade da minha mãe, mas eu não quero voltar para casa porque tenho seis irmãos e a gente não se entende, a gente briga muito... Eles não entendem minha sexualidade. Uma vez por mês ela vem me procurar e traz dinheiro pra mim. Sinto saudade dela, mas não volto pra lá não! (PS, 27 anos, em situação de rua).

Eu não aguentei viver na casa da minha mãe por causa do meu padrasto que é muito violento (SS, 23 anos, gestante do terceiro filho, em situação de rua).

Entende-se que a vulnerabilidade econômica pode promover uma dispersão familiar. Nessa situação, geralmente, as mulheres se tornam provedoras do lar, enquanto os maridos saem de casa. Agier (1990), por meio de uma pesquisa antropológica realizada com 18 famílias moradoras do bairro da Liberdade, em Salvador, verificou que $40 \%$ a $50 \%$ das casas são chefiadas por mulheres cujas rendas são mais baixas, mas que sobrevivem com a ajuda de familiares e vizinhos. Por outro lado, para o sexo masculino, tal realidade pode culminar no abandono do lar, por se sentir destituído do papel de provedor. A partir dessa situação de abandono, um percurso comum encontrado pelo homem é justamente a rua. Diante dessa constatação, é possível, então, explicar o fato de a maioria da população de rua ser do sexo masculino.

\subsection{Saúde}

De acordo com a Organização Mundial da Saúde (OMS), a saúde é considerada como o perfeito estado de bem-estar físico, mental e social, no qual se considera as diversas esferas biopsicossociais do indivíduo. Corroborando com o conceito da OMS, Brasil (1986) assinala que a saúde é resultante de condições de habitação, alimentação, saneamento, educação, renda, trabalho, emprego, lazer, 
acesso a serviços de saúde, a esporte e à cultura, dentre outros fatores. Portanto, as condições vivenciadas em situação de rua estão distantes dos requisitos concebidos em uma perspectiva ampla de saúde.

Contudo, os resultados indicam que as pessoas que se encontram em situação de rua utilizam o discurso da saúde como a ausência da doença. Sendo assim, a saúde está associada à capacidade de resistir às dificuldades enfrentadas no cotidiano, enquanto o conceito de doença está vinculado à impossibilidade de lutar pela sobrevivência (AGUIAR; IRIART, 2012). Vale ressaltar ainda que a própria condição de viver na rua, com todas as carências que a situação oferece, contribui para a dificuldade desse grupo populacional ser considerado sadio.

Ao serem questionados sobre os problemas de saúde, 195 dos 131 entrevistados afirmaram que não possuíam problemas de saúde, o que corrobora a percepção de que, para essas pessoas, estar saudável é simplesmente não apresentar doença. Apenas 64 indivíduos responderam que possuem algum problema de saúde, o que corresponde a aproximadamente $32 \%$. As principais doenças apontadas por essas pessoas se referiam aos casos de hipertensão, diabetes e problemas mentais.

Em relação aos problemas mentais, Pondé (2008) estima que 38\% da população em situação de rua possui algum tipo de transtorno mental. Essa pesquisadora ressalta a polêmica sobre a questão dos manicômios, reabrindo o debate em relação ao atual sistema de atenção à saúde mental. Depois da reforma manicomial, que culminou no fechamento de três hospitais psiquiátricos em Salvador, com 1.200 leitos, a população portadora de transtornos mentais, residindo nas ruas, cresceu assustadoramente.

Os discursos obtidos via entrevistas semiestruturadas apontam para a possibilidade de existir um círculo vicioso. Tanto a pessoa com transtorno mental pode se tornar propícia a morar nas ruas, como também a vida nas ruas, com a propensão ao vício, pode desencadear algum tipo de transtorno mental:

\footnotetext{
Ah, tem morador de rua que não aguentou e ficou maluco. Eu conheço um morador de rua doente, acho que é depressão... acho que fizeram alguma coisa para ele. A mãe vem desesperada, chorando... e ele disse à mãe que não é mais para vir para cá. Ele só quer comida do lixo... Se eu tiver duas quentinhas e der uma para ele, ele não quer... no começo ele tomava banho, mas agora nem toma mais (FC, 60 anos, em situação de rua).
} 
Outro ponto questionado foi a relação dessa população com os serviços públicos de saúde. Nesse ponto, as porcentagens aproximadas variaram entre os que procuram os postos de saúde, os hospitais, os pronto-atendimento e os que simplesmente não procuram nenhum serviço. Os postos de saúde $(46 \%)$ apareceram como principal via de contato da população de rua com o sistema de saúde. O que os leva ao posto, geralmente, são os atendimentos rápidos relacionados a dores, febre e recebimento de camisinhas.

Os hospitais foram indicados por $27 \%$ do total de entrevistados que geralmente chegam às grandes emergências, conduzidos pelo SAMU (Serviço de Atendimento Móvel de Urgência). São comuns os relatos sobre casos de atropelamento, espancamento e contusões de pessoas em situação de rua que precisam de um atendimento de grande porte. Contudo, a relação destes pacientes com a unidade termina no momento que a alta médica é assinada, não existe um programa de acompanhamento do caso. Os pronto-atendimentos que também poderiam prestar serviços de emergência ficaram à margem das escolhas, correspondendo apenas a $4 \%$ das respostas.

É interessante observar que uma parcela significativa da população em situação de rua (17\% dos entrevistados nesta pesquisa) não recorre a nenhum serviço de saúde. Em seus discursos, afirmaram não possuírem problemas de saúde e, quando possuíam, "se resolviam por eles mesmos". Alguns mencionaram o uso de folhas e chás. No entanto, a reclamação maior para justificar tal ausência de procura por serviços médicos foi a ineficiência e o preconceito sofrido nos serviços de saúde.

Muitas pessoas em situação de rua, incluindo os que frequentam e os que não frequentam as unidades de saúde, relataram sofrer discriminação, principalmente por parte dos profissionais. Segundo os entrevistados, os profissionais da saúde se negam a atender, são grosseiros, rudes ou propositalmente negligentes por conta da condição de rua ou da aparência. Às vezes, até a falta de um acompanhante ou de documentos pessoais são desculpas para a recusa em atender ou realizar algum procedimento:

\footnotetext{
Eu conheço uma pessoa que não quiseram atender porque ela não tinha documento. Aí depois que resolveram atender, disseram que não podia ficar internada porque não tinha acompanhante... (CB, 50 anos, em situação de rua).
} 
Nessas circunstâncias, atenta-se para o fato de que o caráter medicalizador do serviço público, atrelado ao preconceito e estigma sofridos nas unidades, contribui para o afastamento da população em situação de rua das estratégias de prevenção à doença e a promoção à saúde, propostas pelo Sistema Único de Saúde. Portanto, percebe-se que questões como universalidade, equidade, cuidados higiênicos e curativos são notavelmente distantes da realidade das pessoas em situação de rua, apesar de a Constituição Federal de 1988 prever a garantia do direito à saúde a todos, por meio de medidas que visem à redução dos riscos de doenças e outros agravos, o acesso universal a ações e serviços de promoção, proteção e recuperação (BRASIL, 2001).

\section{Considerações finais}

Este estudo contribuiu para tornar visíveis as condições de vida e de trabalho da população em situação de rua do centro histórico da cidade de Salvador. A partir dos resultados coletados, percebeu-se que a população em situação de rua de Salvador é composta, em sua maioria, por pessoas do sexo masculino, negras, com baixa escolaridade e com algum tipo de experiência e/ou capacitação de trabalho. A maioria aponta a desintegração dos laços familiares como um dos principais fatores para a situação de rua. Contudo, os questionários apontaram que existem diversos outros fatores que estão por trás dos problemas familiares e que culminam na saída do lar, entre eles, o desemprego, o uso de drogas, a violência familiar, a orientação sexual, a morte ou a separação de um dos cônjuges.

Historicamente, as medidas governamentais tomadas em relação a esse segmento populacional se resumem a ações assistencialistas, paternalistas, autoritárias e de "higienização social". Insuficientemente, essas estratégias não englobam certos aspectos relacionados ao histórico desse indivíduo e a expressão de sua subjetividade. Cada pessoa em situação de rua tem uma justificativa para a chegada e permanência nesse ambiente. São contextos e histórias que foram traçadas de forma diferenciada e que geraram identidades que não são perdidas, apesar das carências e privações vividas na rua. Isso faz com que cada indivíduo lide singularmente com as experiências e com os sofrimentos que vivencia. 
A população em situação de rua costuma ser alvo de remoções dos espaços públicos (higienização), da criação de albergues noturnos e medidas de higiene básica. Essa visão se torna incompatível com o complexo processo de reinserção dessas pessoas no seio familiar, no meio laboral, com condições dignas de habitação, alimentação, saneamento, educação, renda, trabalho, emprego, lazer, acesso a serviços de saúde, a esporte e à cultura, dentre outros fatores.

Como uma tentativa de promover a inclusão social, o governo brasileiro, mediante o Decreto Federal 7.053, de 23 de dezembro de 2009, criou a Política Nacional sobre a População em Situação de Rua, a fim de estabelecer diretrizes e rumos que possibilitem a (re)integração dessas pessoas às suas redes familiares e comunitárias, o acesso pleno aos direitos garantidos aos cidadãos brasileiros e o acesso a oportunidades de desenvolvimento social pleno, considerando as relações e significados próprios produzidos pela vivência do espaço público da rua (BRASIL, 2008b).

O Movimento da População de Rua da Bahia (MPR-BA), em parceria com entidades civis e públicas, desde 2009 vem promovendo discussões por meio de Fóruns Permanentes de Discussão da População de Rua, com o objetivo de criar meios para a implementação de políticas públicas para essa população. A partir dessas discussões, em parceria com o Ministério do Desenvolvimento e Saúde (MDS), foi criado o Centro de Referência Especializado para População em Situação de Rua (CREAS-POP), que deve proporcionar vivências para o alcance da autonomia, e estimular, além disso, a organização, a mobilização e a participação social.

Diante da constatação da existência de um grande contingente de pessoas em tal situação, no ano de 2010 o Governo Federal promoveu a realização de um Seminário Nacional de População de Rua para Defensores Públicos de todo o país, objetivando apresentar as demandas e necessidades desse grupo populacional socialmente vulnerável. Os Defensores Públicos do Estado da Bahia, presentes no Seminário, mantiveram o primeiro contato com o Movimento de População de Rua da Bahia. A partir de 2011, a Defensoria Especializada de Direitos Humanos, em parceira com o MPR-BA, iniciou um trabalho de atendimento individual e coletivo com a população em situação de rua e monitoramento dos abrigos noturnos e da Casa de Passagem da cidade de Salvador (BAHIA, 2011). 
Contudo, essas políticas nem sempre são efetivadas, de modo a cumprir o que é determinado na legislação e alcançar níveis mais aceitáveis para qualidade de vida. O que pôde ser observado durante a pesquisa é que a grande parcela dessa população, além de não ser contemplada pelos objetivos da Política, não possui conhecimento da existência da mesma. Para tanto, torna-se fundamental permitir a articulação entre setores, com o intuito de garantir direitos sociais a partir dos direitos humanos, considerando essas pessoas como cidadãos e estabelecendo uma nova relação ética de respeito no trato, no atendimento e no reconhecimento da responsabilidade do Estado, em articulação com a sociedade.

Desnaturalizar é mostrar que a situação de rua não é para ser vista como algo a ser aceito sem ser politizado, como se as pessoas estivessem ali por uma questão da "natureza". Também não se pode culpabilizar o indivíduo por essa situação, pois sabemos que se trata de uma produção social, histórica e coletiva. É necessário politizar, refletindo sobre o porquê da situação, e coletivamente buscar saídas produtivas.

Dessa forma, destaca-se a necessidade em articular e garantir direitos sociais com direitos humanos, respeitando essas pessoas como cidadãos, e tendo uma nova relação ética de respeito no trato e no atendimento. Como cidadania, entendese ter direito à diferença e, nessa perspectiva, uma nova sociabilidade reconhece o outro como um sujeito portador de interesses válidos e de direitos legítimos, o que contribui para reverter ou inibir fenômeno social da situação de rua. Ressalta-se que a responsabilidade com as políticas públicas é de todos: governo, população, universidade. E este artigo se propõe a salientar essa responsabilidade. 


\section{Referências}

AGIER, M. O sexo da pobreza. Homens, mulheres e famílias numa avenida em Salvador da Bahia. Tempo Social; Rev. Social, USP, S. Paulo, v. 2, n. 2, p. 35-60, 1990.

AGUIAR, M. M. Condições de existência, corpo e saúde entre a população em situação de rua em Salvador, Bahia: uma abordagem antropológica. 2010. 170p. Dissertação (Mestrado em Saúde Coletiva) - Instituto de Saúde Coletiva, Universidade Federal da Bahia, Salvador, 2010.

AGUIAR, M. M.; IRIART, A. B. Significados e práticas de saúde e doença entre a população em situação de rua em Salvador, Bahia, Brasil. Cad. Saúde Pública, Rio de Janeiro, v.28, n. 1, jan. 2012. Disponível em:

$<$ http://www.scielo.br/scielo.php?pid=S0102-

311X2012000100012\&script=sci_arttext>. Acesso em: 30 jun. 2014.

BAHIA. Defensoria Pública do Estado da Bahia. Concurso de práticas exitosas. $\mathbf{X}$ CONGRESSO NACIONAL DE DEFENSORES PÚBLICOS. Salvador - BA. Setem. 2011. Disponível em:

<http://www.defensoria.sp.gov.br/dpesp/Repositorio/31/Documentos/Pratica\%20Exit osa $\% 20 \% 20$ atua\%C3\%A7\%C3\%A30\%20da\%20Defensoria\%20P\%C3\%BAblica.\%2 OFinal.pdf>. Acesso em: 30 jun. 2014.

BRASIL. Constituição da República Federativa do Brasil: promulgada em 5 de outubro de 1988. 28. ed. São Paulo: Editora Saraiva; 2001.

BRASIL, Ministério da Saúde. $\mathbf{8}^{\mathrm{a}}$ Conferência Nacional de Saúde. Relatório final. Brasília: Ministério da Saúde; 1986.

BRASIL, Ministério do Desenvolvimento Social e de Combate à Fome. Pesquisa Nacional sobre a População em Situação de Rua. 2008a.

. Política Nacional para Inclusão Social da População em Situação de Rua para Consulta Pública. 2008b.

DE SÁ, J. C. T. P. A invisibilidade social, uma perspectiva fenomenológica. VI Congresso Português de Sociologia. Mundos Sociais: Saberes e Práticas.

Universidade Nova de Lisboa. Faculdade de Ciências Sociais e Humanas. 25-28 de junho, 2008.

ESCOREL, S. Vidas ao Léu: trajetórias de exclusão social. Rio de Janeiro: Editora Fiocruz, 2006.

Vidas ao Léu: uma etnografia da exclusão social. 1998. 320p. (Tese de Doutorado) - Departamento de Sociologia, Universidade de Brasília, Brasília, 1998. 
PONDÉ, M. A população de rua cresceu $30 \%$ depois da reforma manicomial. Correio, Bahia, nov. 2008. Disponível em:

<http://www.correio24horas.com.br/detalhe/noticia/a-populacao-de-rua-cresceu-30depois-da-reforma-manicomial/?cHash=d34b89afa14ab8f38a303d1f0998e398>. Acesso em: 11 nov. 2008.

ROSA, C. M. M. Vidas de Rua. São Paulo: Editora HUCITEC; REDE RUA, 2005.

SARTI, C. A. A família como espelho: um estudo sobre a moral dos pobres. São Paulo: Cortez, 2009.

SILVA, M. L. L. da. Mudanças recentes no mundo do trabalho e o fenômeno população em situação de rua no Brasil 1995-2005. 2006. Dissertação (Mestrado em Política Social) - Departamento de Serviço Social, Universidade de Brasília, Brasília, 2006.

VARANDA, W. ADORNO, R. C. F. Descartáveis urbanos: discutindo a complexidade da população de rua e o desafio para políticas de saúde. Saúde sociedade, São Paulo, v. 13, n.1, jan./abr. 2004.

WILLIG, C. Introducing Qualitative Research in Psychology. Nova lorque: Open University Press, 2008.

Artigo:

Recebido em: 05/08/2013

Aceito em: 04/07/2014 